\title{
Setting the tone: early interaction patterns in swift starting teams as a predictor of effectiveness
}

Citation for published version (APA):

Zijlstra, F. R. H., Waller, M., \& Phillips, S. (2012). Setting the tone: early interaction patterns in swift starting teams as a predictor of effectiveness. European Journal of Work and Organizational Psychology, 21(5), 749-777. https://doi.org/10.1080/1359432X.2012.690399

Document status and date:

Published: 24/09/2012

DOI:

10.1080/1359432X.2012.690399

Document Version:

Publisher's PDF, also known as Version of record

Document license:

Taverne

Please check the document version of this publication:

- A submitted manuscript is the version of the article upon submission and before peer-review. There can be important differences between the submitted version and the official published version of record.

People interested in the research are advised to contact the author for the final version of the publication, or visit the DOI to the publisher's website.

- The final author version and the galley proof are versions of the publication after peer review.

- The final published version features the final layout of the paper including the volume, issue and page numbers.

Link to publication

\footnotetext{
General rights rights.

- You may freely distribute the URL identifying the publication in the public portal. please follow below link for the End User Agreement:

www.umlib.nl/taverne-license

Take down policy

If you believe that this document breaches copyright please contact us at:

repository@maastrichtuniversity.nl

providing details and we will investigate your claim.
}

Copyright and moral rights for the publications made accessible in the public portal are retained by the authors and/or other copyright owners and it is a condition of accessing publications that users recognise and abide by the legal requirements associated with these

- Users may download and print one copy of any publication from the public portal for the purpose of private study or research.

- You may not further distribute the material or use it for any profit-making activity or commercial gain

If the publication is distributed under the terms of Article $25 \mathrm{fa}$ of the Dutch Copyright Act, indicated by the "Taverne" license above, 


\section{Setting the tone: Early interaction patterns in swift-starting teams as a predictor of effectiveness}

Fred R. H. Zijlstra, Mary J. Waller \& Sybil I. Phillips

To cite this article: Fred R. H. Zijlstra, Mary J. Waller \& Sybil I. Phillips (2012) Setting the tone: Early interaction patterns in swift-starting teams as a predictor of effectiveness, European Journal of Work and Organizational Psychology, 21:5, 749-777, DOI: 10.1080/1359432X.2012.690399

To link to this article: https://doi.org/10.1080/1359432X.2012.690399

曲 Published online: 24 Sep 2012.

Submit your article to this journal $\pi$

Џll Article views: 1073

Q View related articles $\asymp$

4 Citing articles: 14 View citing articles 준 


\title{
Setting the tone: Early interaction patterns in swift-starting teams as a predictor of effectiveness
}

\author{
Fred R. H. Zijlstra ${ }^{1}$, Mary J. Waller ${ }^{2}$, and Sybil I. Phillips ${ }^{3}$ \\ ${ }^{1}$ Department of Work and Social Psychology, Maastricht University, \\ Maastricht, The Netherlands \\ ${ }^{2}$ Schulich School of Business, York University, Toronto, Canada \\ ${ }^{3}$ Institute of Aviation, University of Illinois at Urbana-Champaign, \\ Champaign, IL, USA
}

\begin{abstract}
Many organizations rely on the functioning of teams. In this study we focus on swift-starting teams - that is, ad hoc teams formed for immediate task performance, such as emergency or rescue teams or aviation crews, with highly trained members who have generally not previously worked together as a team. Previous research suggests that teams develop task performance capability over time, but that stable patterns of interaction in teams emerge very quickly. We suggest that these interaction patterns help swift starting teams engage in immediate task performance. In particular, we hypothesize that effective teams will exhibit more interaction patterns, but fewer unique patterns, than less effective teams. We describe an observational study of 18 swift-starting aviation crews. Our results identify the early emergence of specific interaction patterns and indicate significant differences between the patterns of effective and ineffective crews. The effective teams in our sample exhibited patterns that were more stable in duration, more stable in complexity, and more reciprocal as compared to those of less effective teams. We close with implications for work on team interaction, and suggestions for future research and team trainers.
\end{abstract}

Keywords: Team interaction; Behavioral patterns; Team effectiveness; Aviation crews; Swift-starting teams.

Correspondence should be addressed to Fred R. H. Zijlstra, Department of Work and Social Psychology, PO Box 616, Maastricht University, Maastricht 6200 MD, The Netherlands. E-mail: fred.zijlstra@maastrichtuniversity.nl

We thank Alex De Voogt, Robert van Doorn, Rachel Katterl and Fletcher Chauncy for their help in data coding.

(C) 2012 Psychology Press, an imprint of the Taylor \& Francis Group, an Informa business http://www.psypress.com/ejwop

http://dx.doi.org/10.1080/1359432X.2012.690399 
Teams have become very important to organizations in recent decades. It has been well documented that organizations try to adapt to unpredictable, fastpaced environments by forming team-based structures (Barua, Lee, \& Whinston, 1995; Bennis, 1965; Huber, 2004; Mohrman, Cohen, \& Mohrman, 1995). While teams provide the means to decentralize decision-making power (Richardson, Vandenberg, Blum, \& Roman, 2002), enhance cross-functional cooperation (Pinto, Pinto, \& Prescott, 1993), and create knowledge in organizations (Argote, 1999), they also provide organizations with leverage through their flexible deployment. As demand shifts or critical unexpected events emerge, teams can be quickly formed and deployed to match organizational or societal needs.

In order to deal with unexpected events and emergencies, organizations often deploy teams that have specifically been created for these situations. These temporary teams are referred to as action teams and consist of highly skilled specialists that cooperate in events that require improvisation in unpredictable circumstances (Hollenbeck, Beersma, \& Schouten, 2012; Sundstrom, De Meuse, \& Futrell, 1990). These teams must begin task performance activities as quickly as possible, and their members must interact to perform complex, coordinated work (McKinney, Barker, Davis, $\&$ Smith, 2005). For example, ad hoc teams in healthcare organizations form rapidly in order to immediately address complex problems and emergencies (Marsch et al., 2005). Similarly, news organizations rely on teams of journalists to form and begin immediate coverage of unexpected events around the world (Archibold, 2003), later disbanding to follow different emerging events elsewhere. Flight crews in airlines are constantly formed and disbanded by rostering systems designed to meet a tangled array of logistical demands and events, and crew members are expected to effectively fly together immediately after meeting each other (Ginnett, 1987).

In many action teams, membership is based on who happens to be on shift or assigned to duty at the time and place of team formation. As a result, teams with low levels of familiarity are quickly formed to address critical, time-pressured situations with no time to explore personal similarities and differences, or to settle into familiar roles and go through the team development processes as described in the classic group literature (e.g., Lacoursiere, 1980; Tuckman, 1965; Tuckman \& Jensen, 1977). However, previous research also suggests that the initial moments of team development prior to work activities are extremely important to subsequent team outcomes (Eriksen \& Dyer, 2004). In this period, teams normally develop and build the trust that helps communication patterns involved in exchanging and sharing information, which are crucial for team performance (Uitdewilligen, Waller, \& Zijlstra, 2010).

Since these swift-starting teams have little time together before engaging in cooperative task performance, understanding more about their initial 
patterns of interaction may provide insight into their subsequent effectiveness. As Gersick and Hackman note, whether teams create their patterns of interaction routines or import them from members' previous experiences, "both processes result in routines getting established very early in the life of the group, and established very quickly with little or no time specifically devoted to hammering them out" (1990, p. 78). Furthermore, early team interaction patterns tend to be extremely persistent, affecting team processes after initial team formation (Feldman, 1984; Ginnett, 1987), but little research exists regarding the relationship between such patterns and overall team effectiveness in new teams that engage in immediate task performance. Accordingly, we focus here on identifying stable patterns in the early interactions of new swift-starting teams, and on the relationship between these patterns and subsequent team effectiveness.

In the following section, drawing on previous work concerning team development processes and the emergence of patterns and routines in teams, we develop specific hypotheses linked to this focus. We describe a study of newly formed flight crews in their initial stage of activity, and analyse how their early interaction patterns develop over time. By doing so, we hope to extend knowledge concerning both team interaction and team effectiveness by comparing initial interaction patterns between more and less effective crews. We close with implications for future research and for trainers of teams that must make a swift start.

\section{SWIFT-STARTING TEAMS}

Action teams consist of "highly skilled specialist teams cooperating in brief performance events that require improvisation in unpredictable circumstances" (Hollenbeck et al., 2012; Ziegert, Klein, \& Xiao, 2001)circumstances such as crisis management situations in the civilian domain (Schraagen, Huis in 't Veld, \& de Koning, 2010). A subcategory of action teams are swift-starting teams, which are newly formed, ad hoc teams composed of highly trained individuals who must engage in the immediate interdependent performance of complex tasks (McKinney et al., 2005). In general, swift-starting teams involve (1) members who are competent and familiar with their complex work environments, (2) teams working quickly under situations of very evident time pressure, (3) stable roles but ad hoc team membership, and (4) complex, interdependent tasks that rely on team members' interactions during the performance and coordinated execution of well-trained skills.

Although it is possible that members of swift-starting teams may be acquainted and may have worked together on past teams, swift-starting teams generally have ad hoc, fleeting, or even fluid memberships (Klein, Ziegert, Knight, \& Xiao, 2006) with stable roles. For example, upon 
realization of a crisis situation, the Port of Rotterdam brings together toplevel personnel from various organizational functions (e.g., fire brigade captain, police captain, medical adviser) to form a crisis management team (Uitdewilligen \& Waller, 2011); in this swift-starting team configuration, the roles in each crisis management team remain stable, but the individuals occupying the roles change depending on which individuals happen to be on shift at that particular time. As James and Wooten (2010) note, whether the individuals occupying roles remain the same or not, teams with stable role configurations can leverage this stability by developing a set of role-based routines during training simulations. Indeed, some extremely novel and complex crisis situations may require teams with stable roles but with memberships that are fluid and shifting to allow a higher level of response and adaptation (James \& Wooten, 2010). For example, Klein et al. (2006) describe "extreme action teams" that change their memberships in a fluid manner while performing extremely complex tasks, essentially letting the demands of the tasks and non-routine events drive what members the team needs at what times. However, even within these very adaptive teams, a core complement of stable roles exists in the teams across time, although individual team members and some peripheral roles circulate in and out of the team depending on the situation. Importantly, a substantial literature concerning teams in aviation (e.g., Wiener, Kanki, \& Helmreich, 1994), medicine (e.g., Tschan et al., 2006), nuclear power plants (e.g., Waller, Gupta, \& Giambatista, 2004), and other high-reliability contexts suggests that even given the stability of role- and expertise-based routines, teams with highly trained, role-occupying members may still exhibit a wide range of behaviors and interactions during task performance, leading to different levels of team effectiveness.

In addition to the presence of stable roles in swift-starting teams, the process of team formation sets these teams apart from other organizational teams. Following Owens, Mannix, and Neale's (1998) assumptions about teams in organizations, we assume the environment of swift-starting teams to be task- and performance-driven; thus, we assume the formation of teams to be motivated chiefly by organizational needs and situational demands, rather than by the social needs of individuals in search of a team. Indeed, swift-starting teams form due to the happenstance propinquity of trained individuals (e.g., nurses and doctors who happen to be on shift during an emergency), by organizational rostering methods (e.g., airline pilots who happen to be assigned to the same flight), or by a combination of the two. Thus, for swift-starting teams, the process of formation does not necessarily entail an initial perception of team attractiveness or an active choice by individuals to join the team. Instead, the formation of swift-starting teams entails the initial coming together, physically or virtually, of individuals who have been identified (or who self-identify) as team members. In contrast to 
this formation activity, the full development of swift-starting teams via the socio-emotional interaction described by many existing models of group and team development is not likely to occur due to the immediate and intense task focus and short duration of the team itself. Yet, the initial interaction between team members may have a pronounced effect on subsequent communication and interaction (Gersick \& Hackman, 1990), and thus the effectiveness of swift-starting teams. Although a person holding a particular role may be expected to take the initiative in a situation, variance emanating from unique individual and team differences still exists, and influences if, when, and how it may be done.

\section{SWIFT-STARTING TEAM INTERACTION PATTERNS}

Marks and colleagues explicated a model of the rhythmic nature of team processes (Marks, Matthieu, \& Zaccaro, 2001) depicting cycles or performance episodes within which teams repeatedly cycle between periods of actions (such as coordination and monitoring) and periods of transition (such as retrospective analysis or goal specification). This and other temporal team models (e.g., Kozlowski, Gully, Nason, \& Smith, 1999) imply that patterns of team activity unfold over time and can vary dramatically, as different teams may structure their actions within a given episode in discrepant ways. One such type of pattern is an interaction pattern. Interaction patterns in teams are defined as recurrent sets of different types of verbalization, typically for the purpose of collective action and coordination (Zellmer-Bruhn, Waller, \& Ancona, 2004). The models described above, combined with evidence that interaction patterns early in a team's time together may solidify or routinize how team members communicate and work together (e.g., Eriksen \& Dyer, 2004), lead us to ask: What types of early interaction patterns in swift-starting teams are associated with team effectiveness?

One possible answer to this question can be found in recent work on group and team development. Much of the existing literature on group and team development suggests that a certain amount of team longevity is required for a team to mature and approach its maximum level of effectiveness. This literature on group development generally rests on stage or life-cycle models (Lacoursiere, 1980; McGrew, Bilotta, \& Denney, 1999; Tuckman, 1965; Tuckman \& Jensen, 1977; Wheelan, 1994), and suggests that groups pass through a sequential set of phases over time. Group effectiveness is seen as dependent in large part on the eventual entry into a task- or productivity-oriented stage "marked by energetic collective work focused on reaching group goals" (Arrow, Poole, Henry, Wheelan, \& Moreland, 2004, p. 83). Other work offers alternatives to a sequential stage view of group development (Bradford, Gibb, \& Benne, 1964; Bales, 1950; 
Gersick, 1988, 1989). A recent departure from stage-based models is work that adopts the perspective of activity cycles - periods of time shorter than the entire lifecycle of the group - and the phases of activity within each cycle (cf. Ancona \& Chong, 1996; Ancona \& Waller, 2007). For example, Marks et al. (2001) proposed a model of team process that entails the episodic simultaneous and sequential performance of goal-oriented action by teams over time. Similarly, Wheelan and Williams' (2003) field study of interaction patterns in ongoing work groups during a group meeting entailed the mapping of interaction patterns and cycles, and categorizing groups based on these pattern characteristics. The authors were able to link specific pattern types to the frequency of work statements, dependency statements, and levels of development across groups.

Whether teams develop over time in a series of sequential phases or during episodic or cyclical action periods, we suggest here that most swift-starting teams conclude their "brief performance events" (Ziegert et al., 2001) and disband before having the time to reach the productive stages, established equilibriums, or advanced activity cycles depicted in many models of group development; additionally, the pressing focus on the task at hand, combined with the high level of familiarity of team members with the task environment in swift-starting teams, likely precludes much of the socio-emotional interaction used in previous work to define stages of team development. However, the interaction patterns that first emerge in a swift-starting team may exert considerable influence on team coordination and effectiveness even though the team quickly disbands. Therefore, considering the very short, task-focused tenure of swift-starting teams, and following Wheelan and Williams (2003) and Ginnett (1987), we focus here on identifying characteristics of the early patterns of interaction most likely to persist and influence swift-starting team coordination and effectiveness. For this we focus on the first 15 to 20 minutes of team interaction.

In line with Zellmer-Bruhn et al.'s (2004) work on team routines, we focused primarily on interaction patterns in teams, and distinguished verbalizations for the purpose of collective action and coordination (commands, questions), and verbalizations that are related to team development (laughter, anger). Whether as an attempt to alleviate social uncertainty and anxiety (Hackman \& Morris, 1975) or due simply to practice in other contexts, individuals tend to form patterns of interaction quickly when they work in teams (Potter, Cooke, \& Balthazard, 2000). Moreover, the interaction patterns that emerge early in a team's life tend to be extremely persistent (Feldman, 1984). For example, Gersick (1988) noted in her in-depth field study that in one team, interactions lasting less than one minute during the first moments of the team's formation "launched interaction patterns that lasted through the first half of the team's 12-week 
calendar" and effectively limited any task progress during that time (Gersick \& Hackman, 1990, p. 77). In their study of project teams, Eriksen and Dyer (2004) found that a well-planned and thorough mobilization and launch effectively provided successful teams with a persistent "script" for future meetings and interactions.

While both Gersick's and Eriksen and Dyer's results concern teams that were not swift-starting, other work provides congruent evidence for swiftstarting teams; Ginnett (1987), for example, found that captains' behaviors during the first moments of flight crew interactions effectively set the tone for crew interactions over the first and any subsequent flights. In general, and as Feldman observes, the "first behavior pattern that emerges in a group often sets group expectations" (Feldman, 1984, p. 52). Some scholars suggest that if patterns of interaction become entrenched, they may inhibit the adaptation of teams later to unexpected crisis situations (Gersick \& Hackman, 1990); however, as noted by Zellmer-Bruhn and colleagues (2004), stable patterns of interaction in teams may improve efficiency by reducing uncertainty and saving time by eliminating the need to deliberate over who should say what or ask whom each time a situation is encountered. For example, when a command is issued, it is likely that a response will follow; likewise a "question" will generally be followed by an "answer". These are two examples of simple interaction patterns that facilitate the coordination of a team's activities. However, a co-pilot who seemingly randomly vacillates between offering lengthy suggestions for some tasks and remaining silent during other similar tasks may increase uncertainty and reduce the efficiency of both pilots, especially when compared to an aviation crew in which the co-pilot engages in more stable, predictable task communication. As a consequence, one could argue that when comparing the overall predictability of communication - that is, the amount of communication that falls into any pattern - we might see less patterned communication in less effective teams. In other words, the portion of communication that falls into no pattern at all is higher in less effective teams. Given the paramount needs in swift-starting teams to save time and begin immediate and efficient task execution, we hypothesize:

Hypothesis 1: Early in their interaction, effective swift-starting teams engage in more patterned communication than do ineffective swiftstarting teams.

While the hypothesis above pertains to the overall frequency of patterned interaction, it does not specify how many unique patterns might occur in that interaction. A pattern of interaction can be any sequence of behavioral categories that occurs more than could be expected on a random basis. For example, the sequence of asking a question and providing an answer is a 
pattern that is more likely to happen in this order than the reverse order. The different combinations of behaviors are likely to occur several times, and thus are seen as patterns of behavior. Unique patterns differ from each other; a pattern with a behavioral sequence "question-question-command" is different from the pattern "command-question-command". They are both unique patterns. Furthermore, a team might exhibit two unique patterns of interaction, but engage in each pattern five times; a different team may exhibit five unique patterns of interaction, but only engage in each pattern twice. Both teams would exhibit the same amount of patterned interaction (i.e., 10 occurrences), but the second team would spend significantly more time switching from one pattern to another, all else being equal, which could be detrimental to the efficiency of team coordination. Supporting this reasoning, Kanki and colleagues (Kanki, Folk, \& Irwin, 1991; Kanki \& Foushee, 1989; Kanki, Lozito, \& Foushee, 1989) found that higher performing teams created a constrained set of unique interaction patterns, while lower performing teams created a wide range of complex interaction patterns that involved more switching among actors and combined numerous smaller patterns.

Kanki and colleagues interpreted the low number of unique interaction patterns in the higher performing teams as the adoption of a straightforward, standard form of communicating, and the complexity and heterogeneity of lower performing teams' patterns as the relative absence of such a straightforward, standard form. Although this previous work focuses chiefly on the range of patterns across teams, we suggest here that a similar difference occurs within teams - namely, that effective teams exhibit fewer unique interaction patterns of less complexity than do less effective teams. Accordingly, we hypothesize:

Hypothesis 2: Early in their interaction, effective swift-starting teams develop significantly fewer unique patterns of interaction than do ineffective swift-starting teams.

In addition to the creation of patterns of interaction that facilitate team coordination processes, the timing of interaction patterns may also influence the effectiveness of swift-starting teams. For example, in her study of airline flight crews, Waller (1999) found that higher performing crews typically followed the occurrence of non-routine events with interactions concerning task prioritization and resource allocation, and did so more quickly than did lower performing crews. Consistent with Kanki and colleagues (see above), Stachowski, Kaplan, and Waller (2009) also found that higher performing teams had significantly fewer patterns, less complex patterns, and shorter patterns than did lower performing teams. Given our assumptions here that swift-starting teams are embedded in task-focused environments and are compelled to engage in immediate task execution, it seems reasonable to 
expect the initial patterns of interaction in such teams to revolve around task execution as well. Based on the existing results described above, it can be argued that effectiveness in communication is related to the frequency, length, and complexity of patterns. Therefore, we focus here on extending this existing work and suggest that higher performing teams exhibit fewer fluctuations among their interaction patterns, thus enabling even higher levels of predictability and rapid coordination. We therefore expect that interaction patterns of high performing teams will be more stable as expressed in less variation in duration (length) of the communication pattern, and fewer fluctuations in the levels of communications (complexity). We used changes in standard deviations as indicators of stability: A smaller standard deviation means more stability. Thus, we hypothesize:

Hypothesis 3: Early in their interaction, effective swift-starting teams exhibit initial patterns of interaction that vary significantly less in duration than those of ineffective swift-starting teams.

Hypothesis 4: Early in their interaction, effective swift-starting teams exhibit initial patterns of interaction that vary significantly less in complexity than those of ineffective swift-starting teams.

Finally, the work of Meyerson, Weick, and Kramer (1996) suggests that effective temporary teams establish patterns indicating "swift trust" very early in their interactions, and that team members trust each other immediately due to their categorical judgements of other team members based on positive stereotypes. The professional context (i.e., medicine, aviation, etc.) within which swift-starting teams operate, as well as members' highly trained status, may create a preliminary sense of trust through the expectation that professional norms and standards will be followed by all team members. Importantly, Jarvenpaa and Leidner (1999) found in their study of virtual temporary teams that the pattern of action initiation by team members followed by responses from other team members was linked to higher levels of trust in teams. Other research focusing on swift-starting teams suggests that higher performing teams exhibit more reciprocal interaction patterns than do other teams (Kanki, Palmer \& Veinott, 1991). A reciprocal interaction pattern is a pattern in which the parties of an interaction participate in a balanced, two-way exchange. Given the relationship between trust and team effectiveness (Costa, Roe, \& Taillieu, 2001; Edmondson, 1999; Korsgaard, Schweiger, \& Sapienza, 1995), we hypothesize:

Hypothesis 5: Early in their interaction, effective swift-starting teams exhibit more reciprocal patterns of interaction than do ineffective swiftstarting teams. 
To summarize, although previous research on project teams, virtual teams, and swift-starting teams suggests important effects of initial development activity and interaction patterns that emerge early in teams, we know little about how development and interaction patterns influence the effectiveness of swift-starting teams. For our study of such development, we have chosen to focus on newly formed aviation flight crews as they train in a flight simulator. Members of flight crews working for commercial airlines are often scheduled to work together as strangers, only becoming acquainted on their first meeting on the flight deck or in the flight preparation room. Many flight crews are composed of two pilots and may be considered to be dyads or teams. We are aware that the status of dyads as teams has been debated in recent literature (Moreland, 2010; Williams, 2010), with some in favor of and some opposed to the classification of dyads as teams. Here, while acknowledging that some aspects of team behavior and dynamics (for example, network emergence) cannot be ascertained through the study of dyads, we follow Williams' perspective on teams, relying on the definition of team as "a distinguishable set of two or more people who interact, dynamically, interdependently, and adaptively toward a common goal/ objective/mission, who have each been assigned specific roles or functions to perform, and who have a limited life-span of membership" (Salas, Dickenson, Converse, \& Tannenbaum, 1992, p. 4; see also Hackman, 1993). All aspects of this definition apply to a flight crew, and thus from this perspective, dyads are the smallest form of teams.

A flight crew consists of a captain and a first officer, which indicates the hierarchy within this team. The role of captain refers to the responsibilities for the entire crew (including cabin crew) and passengers with respect to safety. However, while flying the airplane, the roles are generally geared towards operating the aircraft, and each of the two pilots performs the role of pilot flying (PF) and pilot not flying (PNF) in either the inbound or outbound leg of the flight. This division of roles refers to the specific tasks the pilots have during the flight (i.e. navigation, communication with air traffic control, aircraft handling, monitoring and balancing fuel, and so on). In every instance pilots must communicate and consult with each other before taking any action, as they both must be aware of and agree with the steps taken in the various procedures. This requires interacting with each other in order to establish and maintain a shared mental model of the situation. Typically pilots are assigned flights according to an individual rostering system, and they must begin working immediately as a team, without knowing each other from previous flights. Very often they meet for the first time during pre-flight preparation.

A theoretical (and practical) reason for this choice of sample could be that since there is very little information available to address our topic, it may be good to begin empirical inquiry with situations that are relatively 
unambiguous and not very complex as far as the interactions are concerned. For these reasons, we will describe a study of 18 newly formed aviation flight crews, and present results based on detailed analyses of the crews' interactions during their initial pre-flight activities.

\section{METHOD}

We investigated early interaction patterns of swift-starting teams by collecting data from newly formed flight crews during their first interactions together (i.e., the flight preparation phase-lasting approximately 15-20 minutes) in flight simulator training sessions conducted as part of a semester-long aviation course. Each crew consisted of two licensed pilots who were undergoing their initial training as members of multi-pilot aviation flight crews; none of the pilots in our sample had prior experience flying as a crew member with another pilot. All participants were FAAlicensed pilots enrolled in a crew resource management (CRM) course as part of an aeronautics programme at a large Midwestern university in the United States. For our data collection we relied on procedures and methods of data collection that have been used in previous studies of team dynamics with pilot teams (Foushee, 1984; Ginnett, 1990; Kanki, 1996; Kanki \& Foushee, 1989). In addition we used a pattern recognition algorithm to identify and characterize interaction patterns in team process data that was previously used by Stachowski et al. (2009). This procedure will be outlined in more detail below.

We collected data from 18 crews as they prepared to "fly" their first leg of flight together as a crew in a stationary flight simulator. Each simulator flight was videotaped. The simulator included all instrumentation and manual controls found in a light twin-engine aircraft such as a Beechcraft Duchess or Piper Seminole. Pilots were randomly assigned to the role of PF (left seat) or PNF (right seat). The hierarchical role elements referring to the roles of captain and co-pilot were not emphasized in these sessions as there were no passengers or other crew members.

The leg of simulated flight followed a scripted scenario that included origination, destination, route, air traffic control information, weather information, and any non-routine events (e.g., engine malfunctions, systems failures, or weather-related events) that were scripted to occur. Scenarios were developed by the flight instructors teaching the course, in accordance with Federal Aviation Administration guidelines. Pilots were aware that their crew performance in the simulator comprised $25 \%$ of their course grade and impacted the flight instructors' overall assessments of their flying skills; thus, the context was both realistic and consequential for participants' professional flight certifications. All pilots in the class volunteered to participate in the study. One of two flight instructors observed each leg of 
flight flown by each crew. Both flight instructors had extensive licensure and experience in aviation training, and both had worked as commercial pilots. During each flight simulation, the flight instructor sat behind the two pilots and played the role of ground operations and air traffic control personnel during the simulation, using information scripted for that flight. After each videotaped simulator flight, the instructor rated crew effectiveness using the LINE/LOS behavioral marker checklist (Helmreich, Merritt, \& Wilhelm, 1998), which is widely cited in the aviation literature and is the basis of many airlines' crew effectiveness evaluations (Flin \& Martin, 2001). The checklist is used to evaluate non-technical team coordination behaviors of crews as they fly actual or simulated flights. It consists of behavioral anchors that instructors use to indicate whether or not specific behaviors have occurred (similar to Behaviorally Anchored Rating Scales-BARS). For example, the dimension "Situational Awareness and Decision Making" includes the following behavioral anchors: Workload and task distribution is clearly communicated and acknowledged by crew members. Adequate time is provided for completion of tasks, e.g., establish well in advance who is flying the leg; establish responsibility for non-routine types of communications. As an additional example, the dimension "Automation Management" includes the behavioral anchor: Crew members verbalize and acknowledge entries and changes to automated systems parameters.

The LINE/LOS checklist requires instructors to rate crew effectiveness for each phase of the flight (i.e., preflight, take-off, cruise, and approach and landing), indicating whether performance is "poor" (significantly below expectations), or meets "minimum expectations" (is less than desired for effective crew operations), or is "standard" (as should normally occur in flight operations), to "outstanding" (truly noteworthy and effective). After the flight, instructors made an assessment of overall crew effectiveness based on their assessments per phase of flight. We used instructors' evaluations of overall crew effectiveness as our measure of crew effectiveness. Crews with assessments of "standard" and "outstanding" were considered to be effective crews (high performers). Of the crews in our study, 11 were assessed to be "low performers" (i.e., rated as "poor" or "minimum expectations") and seven were assessed to be "high performers". Based on these effectiveness ratings, crews were assigned an effectiveness score of 1 (low) or 2 (high) for our analyses.

Each flight simulation was recorded on videotape, and two coders were trained to observe and code the pilots' behavior from video recordings. The two coders independently coded each incidence of a variety of crew member behaviors. The categories of behavior were drawn from previous research on crew communication and coordination behaviors (Kanki \& Foushee, 1989; Kanki et al., 1991) and from previous research on team development (Sarker 
\& Sahay, 2003; Tuckman \& Jensen, 1977). These behavior categories encapsulate the majority of behaviors pilots use in their work (Flin \& Martin, 2001), and the crew behaviors that were coded included those behaviors that are associated with crew communication and coordination (commands, observations, suggestions, enquiries, and answers) and those behaviors associated by previous research with initial team development (disagreeing, laughing, anger, apologies, and non-work communication). The various behaviors that were coded by the raters, their definitions and examples are presented in Table 1.

Following Waller (1999), the entire preflight period was divided in intervals of $10 \mathrm{~s}$, and each type of behavior was coded as present (1) or absent ( 0 ) for every $10 \mathrm{~s}$ interval for each crew. "Preflight" was defined as all activity from the moment the pilots arrived on the simulator flight deck until they received takeoff clearance. The average duration of this segment of flight for the crews we observed was 17 minutes. The title of the pilot engaging in a behavior (PF or PNF) was also recorded, as was the sequential number of the $10 \mathrm{~s}$ interval. Both coders were extensively trained and achieved an inter-coder reliability of 0.82 (Cohen's kappa), indicating a high level of agreement as to the occurrence of the specific behaviors.

TABLE 1

Descriptions and examples of behavioral coding

\begin{tabular}{|c|c|c|}
\hline $\begin{array}{l}\text { Verbalization } \\
\text { type }\end{array}$ & Description & Example \\
\hline Command & $\begin{array}{l}\text { Specific request or } \\
\text { demand for action }\end{array}$ & "Go ahead and input the frequencies" \\
\hline Observation & $\begin{array}{l}\text { Recognizing or noting } \\
\text { a fact or occurrence }\end{array}$ & "We have good weather today" \\
\hline Suggestion & Recommendation for action & $\begin{array}{l}\text { "Maybe we should call the } \\
\text { tower for that" }\end{array}$ \\
\hline Inquiry & Request for information & "What is that supposed to be?" \\
\hline Answer & $\begin{array}{l}\text { Supplying information } \\
\text { for an inquiry }\end{array}$ & "It should be set to $4100 "$ \\
\hline Disagreeing & $\begin{array}{l}\text { Response not in agreement } \\
\text { with a previous statement }\end{array}$ & "No, actually that should be $4200 "$ \\
\hline Laughing & $\begin{array}{l}\text { Laughter or clearly } \\
\text { humorous remark }\end{array}$ & "Ha ha!" \\
\hline Anger & $\begin{array}{l}\text { Comment beyond mere disagreement, } \\
\text { or a ridiculing remark }\end{array}$ & "No, I told you that's wrong!" \\
\hline Apologies & $\begin{array}{l}\text { Remark expressing sorrow } \\
\text { or regret for prior action }\end{array}$ & "Sorry about that" \\
\hline Non-work & Social non-task communication & "Did you have a good weekend?" \\
\hline
\end{tabular}




\begin{abstract}
ANALYSES
The coded data were used to identify patterns in the interactions of the crews. In order to identify patterns of interactions, we used the software algorithm Theme (Noldus Software). This software has been used for a number of years by researchers in animal behavior, psycho-pharmacology, child development and child psychology, sports performance, and also in team research (Ballard, Tschan, \& Waller, 2008; Stachowski et al., 2009) to detect non-obvious temporal patterns of behavior.

Patterns of interaction and behavior can be extremely difficult to detect with the naked eye, especially when other behaviors interrupt the temporal sequence of the behaviors forming a pattern. Such patterns may also be extremely difficult, if not impossible, to detect with procedures such as time series analysis or Markov chains (Magnusson, 2000). In general, the Theme algorithm identifies patterns in sequential data by using three steps. First, the algorithm identifies simple temporal patterns - or "T-patterns" - of two behaviors that occur in time-coded sequential data significantly more often than by chance (see Figure 1). For instance, the sequence: "Question (A)Answer (B)" is a T-pattern, consisting of two behaviors. A T-pattern is "essentially a combination of events in which the events occur in the same order with the real-time differences between consecutive pattern components remaining relatively invariant (i.e., the time difference between $\mathrm{A}$ and $\mathrm{B}$ will be $x+(-y)$ with respect to an expectation assuming, as a null hypothesis, that each component is independently and randomly distributed over time" (Borrie et al., 2002, p. 846). As explained by Magnusson, "if A is an earlier and $\mathrm{B}$ a later component of the same recurring T-pattern, then after an occurrence of $A$ at $t$, there is an interval $[t+\mathrm{d} 1, t+\mathrm{d} 2](\mathrm{d} 2 \geq \mathrm{d} 1 \geq 0)$ that tends to contain at least one occurrence of $\mathrm{B}$ more often than would be expected by chance" (2000, p. 94). In sum, the algorithm detects whether there are sequences of behavior that occur more frequently than would be expected by chance.
\end{abstract}

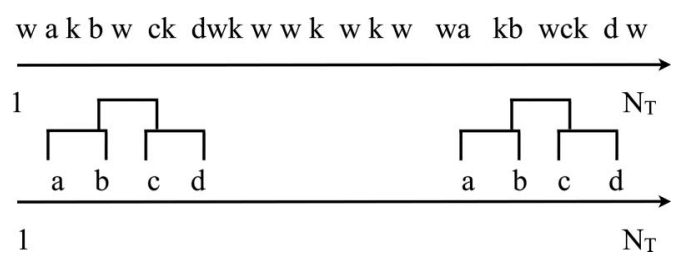

Figure 1. Representation of recurrent T-patterns of behavior (characters represents a behavior on a time line). The characters $\mathrm{w}, \mathrm{a}, \mathrm{k}$, etc. on the top line represent various types of behaviors; the second line shows the recurrent behavior patterns that are hidden in the top line. In fact this figure shows two related T-patterns (a,b and c,d), and this is repeated some time later. 
Second, after simple two-behavior T-patterns are identified, the algorithm cycles through the data, building more complex hierarchical patterns of relationships among T-patterns. This so-called "bottom-up" approach of pattern detection identifies simple patterns first and then detects larger patterns as a combination of the simpler ones. Finally, the algorithm eliminates patterns that are less complete versions of other patterns. For example, as explained by Borrie and colleagues: "a pattern $\mathrm{Q}=(\mathrm{ABCDE})$ may be partially detected as, for example, (ACDE) or (BDE) or (ABCE); since elements of $\mathrm{Q}$ are missing, these three patterns constitute less complete descriptions of the underlying patterning. A newly detected pattern $\mathrm{Q}_{x}$ is thus considered equally or less complete than an already detected pattern $\mathrm{Q}_{y}$ if $\mathrm{Q}_{x}$ and $\mathrm{Q}_{y}$ occur equally often and all events in $\mathrm{Q}_{x}$ also occur in $\mathrm{Q}_{y}$. In this case, $\mathrm{Q}_{x}$ is eliminated" (2002, p. 847)

The algorithm allows the user to select frequency and probability requirements for the patterns detected. In our analyses, we chose to include only those patterns that occurred at least three times during the pre-flight activities for our crews. This criterion of three times was chosen because it implied that the pattern would, on average, occur at least once every five minutes with an average of 17 minutes for the observed periods. Furthermore, we required a $95 \%$ probability that patterns occurred above and beyond chance.

Using the algorithm, we determined the number of times patterns of verbalizations occurred $(\mathrm{H} 1)$, the number of unique patterns generated $(\mathrm{H} 2)$, the length of patterns (H3), the number of levels in pattern hierarchies (H4), and the number of unique mono-actor patterns and their occurrences (H5) for each team. Following Magnusson (2000) and Stachowski et al. (2009), we used the number of levels in the hierarchies of patterns to represent pattern complexity (see Figure 2), and we used the number of unique mono-actor patterns (i.e., patterns of interaction that involve only one person) and the frequency of their occurrences as an inverse measure of the reciprocity or balanced nature of interactions. We chose to use the number of mono-actor patterns and the incidence of these patterns rather than the number of multiactor patterns because multi-actor patterns, while involving both pilots, could mask the fact that a pattern might be dominated by the behavior of one pilot; for example, a recurrent pattern involving one verbalization by Pilot B and four verbalizations by Pilot A would be categorized as a multi-actor pattern, but would mask the domination of the pattern by Pilot A. Conversely, the number of mono-actor patterns represents more clearly the evidence of onesided, non-reciprocal interactions in teams. A mono-actor pattern would be identified if, for example, the same pilot made an inquiry and subsequently answered his or her own inquiry (assuming this pattern met our frequency and probability requirements); if the pilot engaged in this pattern numerous times, the frequency of the pattern's occurrence would also be high. 

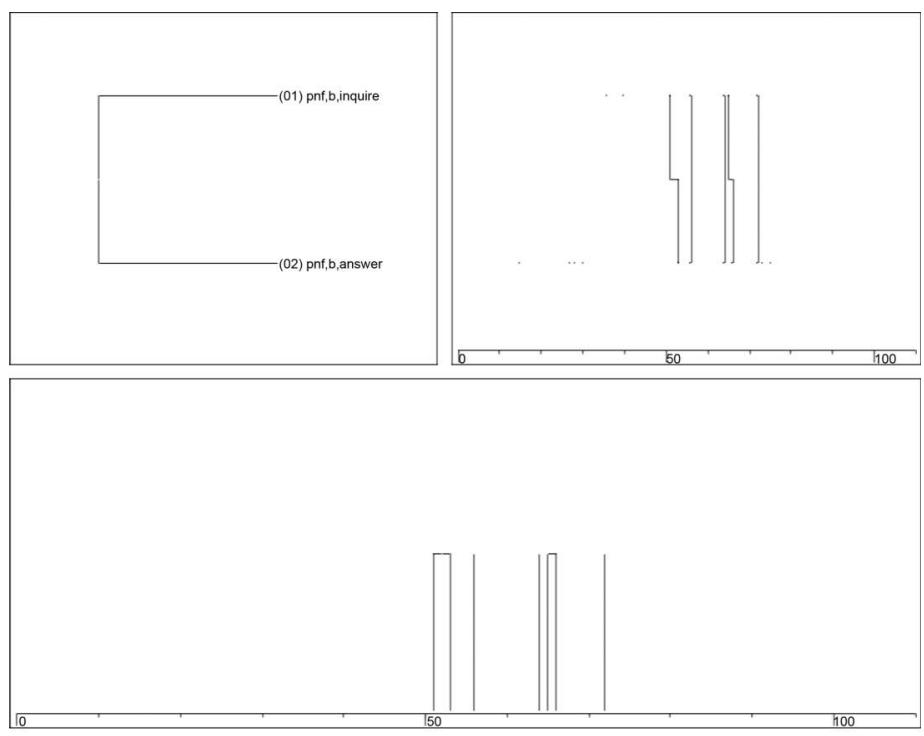

(a)
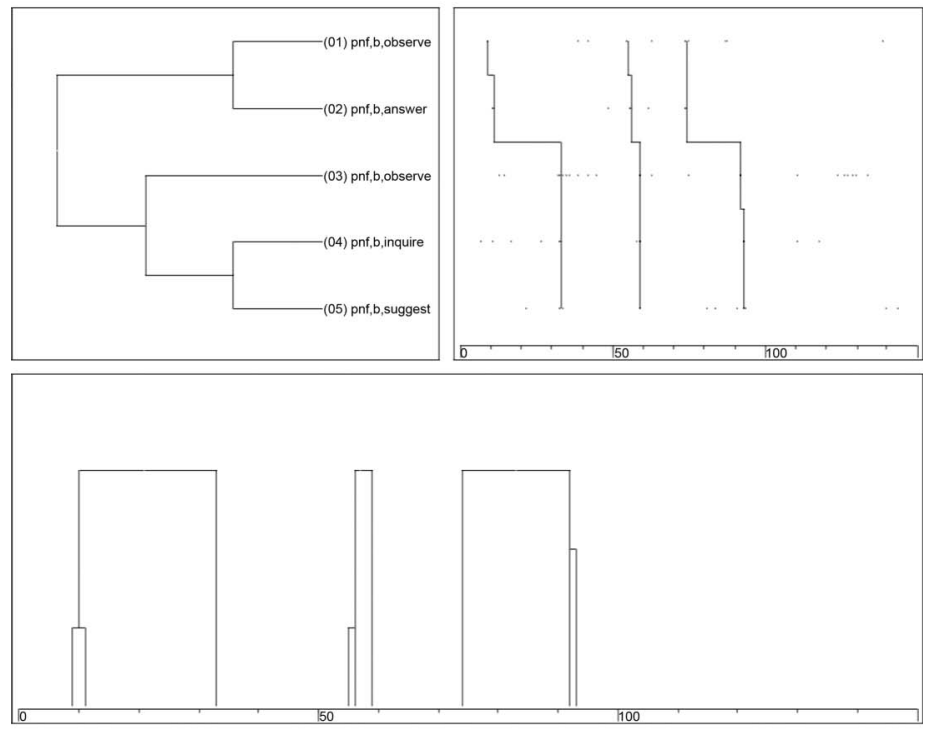

(b)

Figure 2. (a) This represents an example of a "simple pattern" because it involves a pattern with only two behaviors. 01: PNF = pilot not flying has an inquiry; 02: PNF gives an answer. In this example the person answers his own question. (b) This represents a complex pattern due to the multiple levels of T-patterns. 
We used $t$-tests to determine differences in the frequencies of verbalizations and in interaction pattern characteristics between effective and ineffective crews.

\section{RESULTS}

The analysis of interaction patterns using the algorithm revealed that crew interaction did indeed fall into discernible temporal patterns (T-patterns) that occurred significantly more frequently than by chance. This satisfied our analysis parameters and allowed testing of Hypotheses 1 through 5.

Table 2 depicts the descriptive statistics (including means and standard deviations) and Table 3 depicts the correlations for the study variables. Table 3 shows that the number of unique patterns is highly associated with the number of mono-actor patterns $(r=.79)$. This makes sense since mono (one actor) patterns tend to be unusual in a team training setting. Furthermore, Table 3 suggests that the number of mono patterns is highly correlated with the number of mono pattern occurrences $(r=.99)$, such that they are (almost) identical. This also makes sense, certainly in a relatively small sample where the effect of one team member persisting in this behavior is noticeable. However, given this high correlation we will only include number of mono patterns in the analysis.

TABLE 2

Psychometric properties of the major study variables

\begin{tabular}{lccrr}
\hline Parameter & Minimum & Maximum & \multicolumn{1}{c}{$M$} & $S D$ \\
\hline Command & .00 & 8.00 & 2.94 & 2.07 \\
Observation & 12.00 & 39.00 & 23.11 & 8.41 \\
Suggestion & 1.00 & 20.00 & 5.11 & 4.76 \\
Inquiry & 3.00 & 30.00 & 13.22 & 7.46 \\
Answer & 4.00 & 58.00 & 18.22 & 12.56 \\
Disagree & .00 & 9.00 & 1.28 & 2.11 \\
Laugh & .00 & 31.00 & 11.94 & 9.41 \\
Anger & .00 & 2.00 & .17 & .51 \\
Sorry & .00 & 2.00 & .56 & .78 \\
Social & .00 & 6.00 & 1.06 & 1.66 \\
No. patterns & 0 & 16 & 6.83 & 5.40 \\
No. mono patterns & 0 & 5 & 1.33 & 1.41 \\
No. mono pattern & 0 & 25 & 5.72 & 6.70 \\
$\quad$ occurrences & & & & \\
Length & 0 & 2.69 & 1.79 & 1.01 \\
Levels & 0 & 1.69 & .95 & .65 \\
Effectiveness $(1=$ low $)$ & 1 & 2 & 1.39 & .50 \\
\hline
\end{tabular}

$n=18$ teams. 


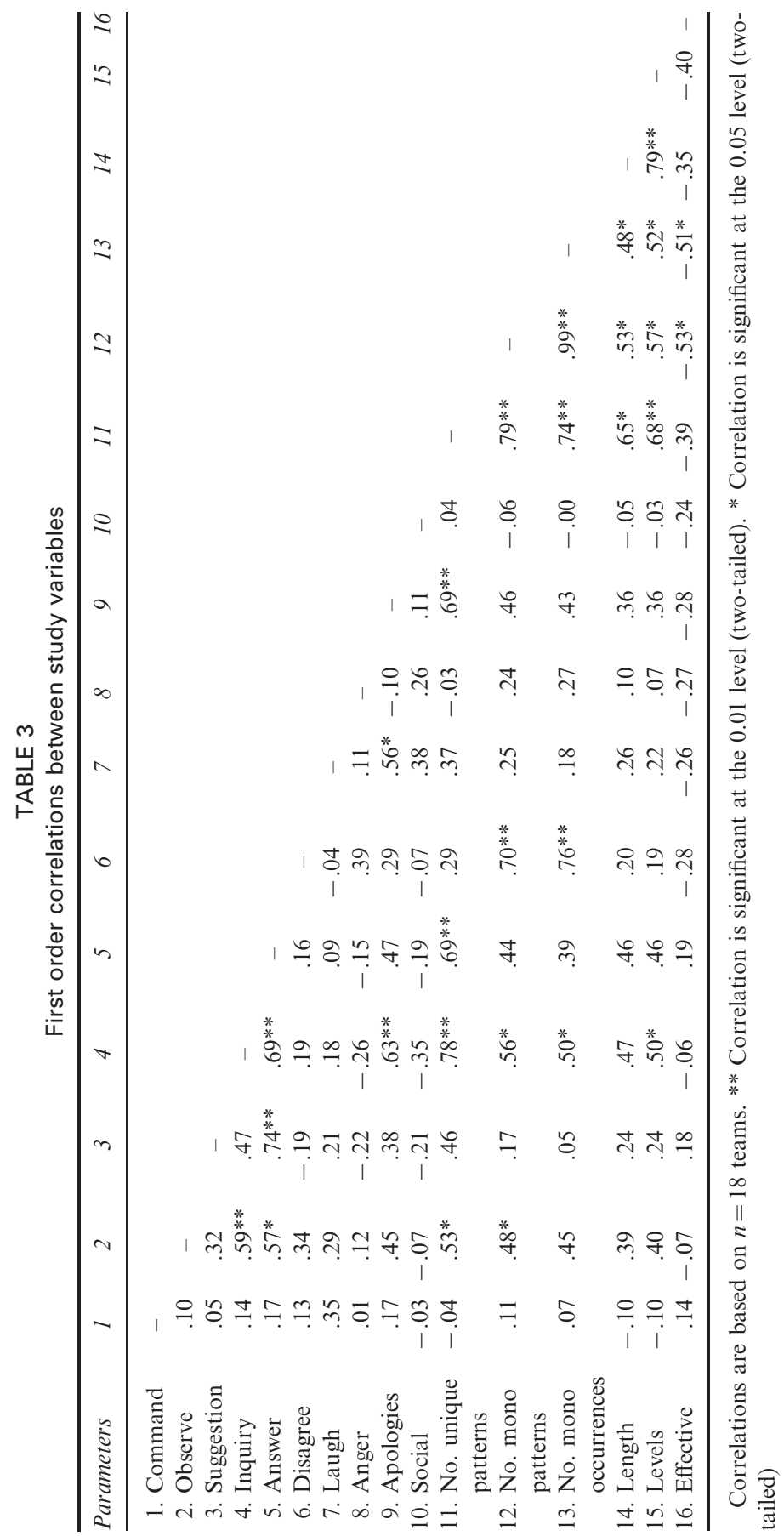


First, we determined whether effective and less effective crews differed with respect to the frequency of coded behaviors. Therefore, we compared the averages for each coded behavior (command, suggestion, etc.) between effective and less effective crews. However, we found no significant difference $(p<.10)$ between these types of crews regarding the number of times they engaged in any of the coded verbalizations. Additionally, we examined the difference in frequency between task-focused interactions and developmentfocused interactions of the crews. Development-focused interactions are expressions that relate to developing a team climate, such as laughing, expressions of anger, social or non-work-related remarks (cf. Bales, 1950). We used a paired $t$-test to compare the averages of the crew communication and coordination verbalizations (i.e., totals of command, observation, suggestion, and inquiry) to the frequencies of the team development verbalizations (i.e., totals of laugh, anger, sorry, social) previously coded. Our crews engaged in significantly more crew communication and coordination verbalizations, $M=62.61 ; S D=28.29$, as opposed to team development verbalizations, $M=15.00 ; S D=10.87, t(17)=7.28 ; p<.001$; $d=3.53$, supporting their identification as task-focused swift-starting teams.

Our next step was to test our hypotheses. Using $t$-tests, we compared the total number of pattern occurrences, total number of unique patterns, stability of pattern length, the stability of the number of hierarchical levels in patterns, and number of mono-actor patterns between the higher and lower effectiveness crews. The results of our $t$-tests are depicted in Table 4 . We formulated specific expectations concerning the direction of the differences between groups, and will therefore test one-tailed. The results show that our first and second hypotheses - that effective teams would engage in more patterned interaction (H1) and have fewer unique patterns (H2) than less

TABLE 4

Comparison of pattern characteristics between low-effective and high-effective crews

\begin{tabular}{|c|c|c|c|c|c|c|c|}
\hline \multirow[b]{2}{*}{ Parameters } & \multicolumn{2}{|c|}{$M$} & \multicolumn{2}{|c|}{$S D$} & \multirow[b]{2}{*}{$t(16)$} & \multirow[b]{2}{*}{$p$} & \multirow[b]{2}{*}{ Cohen's a } \\
\hline & Low & High & Low & High & & & \\
\hline No. pattern occurrences $(\mathrm{H} 1)$ & 40.27 & 24.14 & 26.60 & 27.83 & 1.23 & .118 & 0.62 \\
\hline No. unique patterns (H2) & 8.45 & 4.29 & 5.39 & 4.68 & 1.68 & .056 & 0.84 \\
\hline $\begin{array}{l}\text { Stability in duration of } \\
\text { patterns }(\mathrm{H} 3)\end{array}$ & 0.39 & -0.01 & 0.28 & 0.49 & 2.25 & .019 & 1.13 \\
\hline Stability in levels in patterns (H4) & 0.37 & -0.01 & 0.25 & 0.49 & 2.22 & .018 & 1.11 \\
\hline $\begin{array}{l}\text { No. unique mono-actor } \\
\text { patterns }(\mathrm{H} 5)\end{array}$ & 1.91 & 0.43 & 1.44 & 0.79 & 2.47 & .012 & 1.24 \\
\hline
\end{tabular}

$p$ is based on one-tailed testing. Multiple comparisons require a correction for $\alpha$ inflation. Accepting a chance level of $p=0.10$, this would require a $p \leq .02$ (Bonferroni correction) for a statistically significant result. 
effective teams - were not supported ( $p=.12$ and $p=.06$, respectively). However, the results do indicate that the effective crews in our sample displayed patterns of interaction that had less variation in length $(\mathrm{H} 3$, $p<.02)$ and in complexity $(\mathrm{H} 4, p<.02)$ than those of less effective crews.

Concerning our final hypothesis (H5), we used the number of unique mono-actor patterns to indicate the balanced nature of the interaction between the pilots. Our analysis depicted in Table 4 suggests that interaction patterns of less effective crews are characterized by significantly more unique mono-actor patterns $(p<.02)$ as compared to effective crews.

In order to test the discriminant power of the six pattern characteristics listed in Table 4, we used the discriminant function analysis procedure in SPSS. The model was significant at $p=0.08$, Wilks' $\lambda=0.43, \chi^{2}=11.11$, and indicated that $88.9 \%$ of the crews were correctly classified as effective or less effective by the behavior pattern characteristics. These results suggest that, for our sample, less effective and more effective swift-starting teams exhibit significantly different interaction patterns immediately after beginning their work.

\section{ADDITIONAL EXPLORATORY ANALYSIS}

One of the most striking results in our analysis was the hypothesized difference in the number of mono-actor patterns between the effective and less effective crews. The less effective crews displayed a total of 75 monoactor patterns, while the effective crews displayed a total of 11 such patterns. We suspected that the pilots flying (PFs) were engaging in directive leadership by monopolizing communication in the less effective crews. However, a closer look at our data revealed that in less effective crews, the pilots not flying (PNFs) were responsible for 58 of the 75 mono-actor pattern occurrences. Of these 58 mono-actor pattern occurrences, 25 were an inquiry/answer pattern and 20 were an observation/answer pattern. Thus, our suspicion of authoritarian PFs was incorrect. If anything, the PFs were silent while the PNFs made inquiries or observations, waited for a response, and then proceeded to provide their own answers. We explore possible causes of these patterns of interaction, and other issues, below.

\section{DISCUSSION}

Our study focused on developing more understanding about the early patterns of interaction exhibited by swift-starting teams. Specifically, we focused our efforts on identifying the nature of initial interaction patterns in new swift-starting teams, and on examining the relationship between those patterns and overall team effectiveness. Our preliminary analyses showed that crews in our study displayed significantly more task-oriented behaviors 
than development-oriented behaviors, providing support for our claim that our crews are indeed "swift-starting" teams.

Furthermore, our analyses provided results in several areas. First, we found that the frequencies of various types of coded behaviors during early interactions (H1) did not differ significantly between effective and ineffective teams. Our second hypothesis was also not supported, yet effective crews did seem to have fewer unique patterns, as can be seen in Table 4. The lack of statistically significant support may be due to the somewhat constrained time period for which we observed the crews and the routinized nature of the work. Nevertheless, we found significant differences between effective and ineffective crews' interaction patterns: Effective teams in our sample exhibited patterns that were more stable in duration (H3), more stable in complexity (H4), and more reciprocal (H5) as compared to those of less effective teams.

These findings indicate that effective and ineffective teams did not so much differ with respect to their activity levels (number of counted behaviors), but instead that effective teams displayed qualitatively different interaction patterns as compared to ineffective teams. Early in their interaction, effective teams established patterns of communication that were more stable and balanced. A balanced pattern implies that both crew members are involved in the interaction, indicating more reciprocity in the interaction. This is a prerequisite for exchanging information in order to establish and maintain a shared understanding of the task and situation (Uitdewilligen et al., 2010). By engaging in more mono-actor patterns, the ineffective crews most likely missed opportunities for sharing information, cooperatively making decisions, and developing shared understanding of actions and plans. Our findings clearly suggest that even from its inception, an effective team's interactions are substantially different from those of other teams. Other researchers have also found relationships between interaction patterns and team effectiveness (Jehn \& Mannix, 2001; Waller, 1999; Waller et al., 2004). As previously mentioned, Kanki et al. (1989) found that high-performing flight crews exhibited similar interaction patterns across crews, while lowperforming crews displayed a wide, heterogeneous assortment of patterns across crews. We found similar results while focusing on the characteristics of interaction patterns over time within crews.

Furthermore, we found that the PNFs in ineffective crews engaged in significantly more mono-actor patterns than did other pilots, often posing and answering their own questions or commenting on their own observations. This lack of interaction - whether caused by inattentive, overburdened PFs or overbearing PNFs - was associated with a low level of crew interaction and imbalanced communication between pilots in the ineffective crews. This result supports the conclusions of several studies in communication regarding the positive effects of turn-taking and balanced 
communication in groups (cf. Paulus, 2000). Similarly, research on mental model development suggests that reciprocal, balanced communication among team members results in more information sharing and mental model accuracy (cf. Rasker, Post, \& Schraagen, 2000; Uitdewilligen et al., 2010). This result can also be interpreted as if the natural division of roles in the cockpit between PF and PNF is not the most likely explanation for the mono-actor patterns. If such would be the case, than one would expect that the PF would be responsible for the majority of the mono-actor patterns, as the PF can be expected to have the lead and therefore should initiate most of the interactions. As noted previously, the difference in hierarchy between "captain" and "first officer" is not emphasized in the specific context of this flight simulator training and therefore does not lend itself to a sufficient explanation for these results. Altogether, the results indeed seem to be attributable to interaction styles that develop early in the interaction between members of the crew. These seemingly subtle differences may play a large role in setting the stage for subsequent interaction and effectiveness.

The newly formed crews in our sample established patterns of interaction very early in their work. This suggests that new crews are subject to the same motivation to quickly establish routines, norms, and interaction patterns as are other teams in less technical, non-aviation contexts (see Gersick \& Hackman, 1990). Given the requirement of experienced pilots in commercial aviation to form new crews continuously, the emergence of norms and patterns of interactions in experienced crews may occur even more rapidly than in our novice crews. As the longevity of patterns in teams likely acts to solidify their persistence, more research comparing interaction pattern emergence in novice and expert teams is needed in order to ascertain differences associated with expertise level.

Based on our results, it seems possible that in swift-starting teams, the characteristics of interaction patterns serve as a rapid enactment of characteristics considered in previous literature as hallmarks of mature teams that have developed over time. For example, previous literature suggests that as teams mature, they are more likely to engage in open, balanced communication (see Chang, Bordia, \& Duck, 2003), to have responsive and activated members, and to increase in task coordination and efficiency (Wheelan \& Williams, 2003). In swift-starting teams, these characteristics may be quickly enacted through initial interaction patterns rather than through the socio-emotional communication often used to indicate levels of team development. For example, teams with low monoactor pattern frequency and occurrence enacted higher levels of reciprocity than other teams. Similarly, swift-starting teams with short, simple patterns enacted responsiveness and efficiency in their interactions, and teams with a high number of pattern occurrences enacted coordination as they worked together. Thus, the characteristics of efficient and mature teams suggested by 
previous work may be applicable to swift-starting teams, but may need to be measured by the analysis of interaction patterns rather than by the examination of socio-emotional interactions.

With this study, we have extended previous research by digging deeper to identify subtle differences in team interaction in a routine (as opposed to non-routine or crisis) context. In particular, we replicate and extend the work of Waller et al. (2004), who studied nuclear power crews during routine and non-routine situations, and who also found no significant differences in behavior frequency between high- and average-performing crews during the routine situations. These authors did, however, find that the same crews differed significantly in both adaptive behavior and effectiveness during crisis situations. By specifically examining the critical first moments of team interaction in a new team, we help explain the subsequent bifurcation in behavior and effectiveness during crisis situations that Waller and colleagues (2004) found. It could be that those teams displaying the subtle qualitative differences we saw in the first moments of routine task performance are able later to engage in the adaptive behavior displayed by the high-performing teams in their study. By examining the variation of length and complexity among patterns within teams, we tap into the stability, predictability, and even rhythm of their interaction patterns, as we also do by examining the reciprocity of their patterns.

Additionally, by using the pattern recognition algorithm to analyze our data, we were able to identify such recurrent patterns of interaction embedded within sequential strings of behavioral data. This approach differs from techniques such as Markov chains primarily in that irrelevant behaviors (noise) occurring between the behaviors included in a pattern must not be removed or discounted a priori before the pattern can be detected (see Kerepesi et al., 2005; Stachowski et al., 2009).

Overall, the results of our study demonstrate that for newly formed swiftstarting teams, the first few moments of interaction are consequential for overall team effectiveness. The interaction patterns that are established early are significantly related to effectiveness and, most likely, to the climate in the team. In particular, whether the team manages to establish a climate that is perceived as psychologically safe is important for communication and interaction (Edmondson, 1999); the more "psychologically safe" people perceive the climate in the team to be, the better and more open the communication. Given the time scarcity allowed by a swift-starting context for teams to build interpersonal relationships, this may be particularly important in contexts such as aviation and medicine, which are also hierarchical status relations (i.e., captain-first officer; physician-nurse) that may hamper communication (Lingard, Reznick, Espin, Regehr, \& DeVito, 2002). Training that underscores the importance of early interaction and communication for all hierarchical levels, such as those recommended in many permutations of 
Crew Resource Management training programs (Helmreich et al., 1998) would seem to be particularly important for swift-starting teams.

\section{PRACTICAL IMPLICATIONS}

The findings of this study are relevant for team training, as they demonstrate the importance of a team's first moments of interaction together. The reciprocity of interactions and the avoidance of mono-action patterns are elements that trainers could take into account when training and assessing team performance. Additionally, managers should be aware of the important subsequent influences those early interactions may have. They should monitor the interactions of new teams carefully, watching for teams that seem to have episodes of interaction that obviously vary wildly in terms of length, complexity, or reciprocity. In particular, mono-actor patterns may be easier than the other nuances to identify with real-time observation.

Apart from training consequences, there may also be consequences of this work for research. Although the early interaction patterns we have studied were in a particular context, these patterns, and the methods used for their coding and analysis, can easily be transferred to other contexts, and the important variables in our study ("reciprocity in patterns", number of "unique patterns", "mono-actor patterns", and so on) are in fact "contextfree" elements for the study of team interaction. These methods may facilitate the accessibility of studying other behavioral team processes and interaction patterns in various settings, including a laboratory setting.

\section{STUDY LIMITATIONS}

There are inevitable limitations associated with this study. The limited number of teams participating in it reduces the statistical power of our analyses. However, this is not automatically a problem (cf. Stachowksi et al., 2009), as it also marks the robustness of the effects we report. On the other hand, there is little empirical work detailing the initial interactions of swiftstarting teams composed of highly skilled members, and we strive to offer a view of such interactions here. Further, as Peterson, Smith, and Martorana asked in their defence of small-sample studies: "Is it better to take some risk in publishing small-sample studies that could inspire theory development and large-scale quantitative studies but that also open the field to the possible need for correction through meta-analysis, or is it better to face the risk of having virtually no research at all published on an important topic?" (2006, p. 6). Future studies should examine such causality, along with possible antecedents of the verbalizations and patterns as we observed, with a larger sample of swift-starting teams across multiple contexts. Additionally, although our instructors have many years of experience (and the 
requisite licensure) in training new aviators, and are therefore expert raters of crew effectiveness, we also minimized the subjectivity in ratings by using the LINE/LOS behavioral marker checklist for their assessment; future research should employ more than one expert rater to determine the effectiveness of crews, and should calculate and report inter-rater agreement. We employed a binary division of high/low effective teams based on the LINE/LOS checklist. Using a coarse-grained effectiveness scale could mask the fact that real differences in crew effectiveness were actually quite small; alternatively, our binary measure might mask the fact that instructors were very lenient in their assessment of effectiveness. It should be noted that the crews were only at the beginning of their crew training and that instructors assumed that substantial improvement would be made later, and marked accordingly in order not to discourage students, as instructors and teachers sometimes do. Nevertheless, the differences in effectiveness were real differences, and we have no reason to believe that the flight instructors' assessments of effectiveness were asymmetrically biased among the crews.

In sum, swift-starting teams are critical "first responders" in organizations facing unexpected, complex issues. The ability of individuals to come together and immediately coordinate their efforts successfully can provide organizations with the ability to remain as flexible and responsive as possible in dynamic, complex environments. Based on analyses using a softwarebased technique to identify patterns of interaction, our results suggest that the patterns emerging from the first moments of interaction in these teams may indeed be the harbingers of team success or failure. Future research should examine the antecedents and malleability of early patterns in these important and consequential teams, as understanding and correcting such patterns early may help them avoid the creation or importation of ineffective patterns in their future behavioral repertoires.

\section{REFERENCES}

Ancona, D. G., \& Chong, C. T. (1996). Entrainment: Pace, cycle, and rhythm in organizational behavior. In B. Staw \& T. Cummings (Eds.), Research in organizational behavior (Vol. 18, pp. 251-284). Greenwich, CT: JAI Press.

Ancona, D. G., \& Waller, M. J. (2007). The dance of entrainment: Temporally navigating across multiple pacers. In B. Rubin (Ed.), Research in the sociology of work (Vol. 17, pp. 115-146). Oxford, UK: Elsevier.

Archibold, R. C. (2003, March 22). A nation at war: The new organizations; Papers debate use of teams to react quickly to terror. New York Times.

Argote, L. (1999). Organizational learning: Creating, retaining, and transferring knowledge. Norwell, MA: Kluwer.

Arrow, H., Poole, M. S., Henry, K. B., Wheelan, S., \& Moreland, R. (2004). Time, change, and development: The temporal perspective on groups. Small Group Research, 35, 73-105.

Bales, R. F. (1950). Interaction process analysis: A method for the study of small groups. Chicago, IL: University of Chicago Press. 
Ballard, D. I., Tschan, F., \& Waller, M. J. (2008). All in the timing: Considering time at multiple stages of group research. Small Group Research, 39, 328-351.

Barua, A., Lee, C.-H. S., \& Whinston, A. B. (1995). Incentives and computing systems for teambased organizations. Organization Science, 6, 487-504.

Bennis, W. G. (1965). Beyond bureaucracy. Trans Actions, 2, 31-35.

Borrie, A., Jonsson, G. K., \& Magnusson, M. S. (2002). Temporal pattern analysis and its applicability in sport: An explanation and exemplar data. Journal of Sports Sciences, 20, $845-852$.

Bradford, L. P., Gibb, J. R., \& Benne, K. D. (1964). T-group theory and laboratory method. New York, NY: Wiley.

Chang, A., Bordia, P., \& Duck, J. (2003). Punctuated equilibrium and linear progression: Toward a new understanding of group development. Academy of Management Journal, 46, $106-117$.

Costa, A. C., Roe, R. A., \& Taillieu, T. (2001). Trust within teams: The relation with performance effectiveness. European Journal of Work and Organizational Psychology, 10, 225-244.

Edmondson, A. (1999). Psychological safety and learning behavior in work teams. Administrative Science Quarterly, 44, 350-383.

Eriksen, J., \& Dyer, L. (2004). Right from the start: Exploring the effects of early team events on subsequent project team development and performance. Administrative Science Quarterly, $49,438-471$.

Feldman, D. C. (1984). The development and enforcement of group norms. Academy of Management Review, 9, 47-53.

Flin, R., \& Martin, L. (2001). Behavioral markers for crew resource management: A review of current practice. International Journal of Aviation Psychology, 11, 95-118.

Foushee, H. C. (1984). Dyads and triads at 35,000 feet: Factors affecting group process and aircrew performance. American Psychologist, 39, 886-893.

Gersick, C. J. G. (1988). Time and transition in work teams: Toward a new model of group development. Academy of Management Journal, 31, 9-41.

Gersick, C. J. G. (1989). Marking time: Predictable transitions in task groups. Academy of Management Journal, 32, 274-309.

Gersick, C. J. G., \& Hackman, J. R. (1990). Habitual routines in task-performing groups. Organizational Behavior and Human Decision Processes, 47, 65-97.

Ginnett, R. C. (1987). The formation process of airline crews. In R. S. Jensen (Ed.), Proceedings, Fourth International Symposium on Aviation Psychology (pp. 399-405). Columbus, OH: Ohio State University Press.

Ginnett, R. C. (1990). Airline cockpit crews. In J. R. Hackman (Ed.), Groups that work and those that don't. San Francisco, CA: Jossey-Bass.

Hackman, J. R. (1993). Teams, leaders, and organizations: New directions for crew-oriented flight training. In E. Wiener, B. Kanki, \& R. Helmreich (Eds.), Cockpit resource management (pp. 47-70). San Diego, CA: Academic Press.

Hackman, J. R., \& Morris, C. G. (1975). Group tasks, group interaction process, and group performance effectiveness: A review and proposed integration. In L. Berkowitz (Ed.), Advances in experimental social psychology (Vol. 8). New York, NY: Academic Press.

Helmreich, R. L., Merritt, A. C., \& Wilhelm, J. A. (1998). The evolution of Crew Resource Management training in commercial aviation. International Journal of Aviation Psychology, 9, 19-32.

Hollenbeck, J. R., Beersma, B., \& Schouten, M. E., (2012). Beyond team types and taxonomies: A dimensional scaling conceptualization for team description. Academy of Management Review, 37, 82-106.

Huber, G. P. (2004). The necessary nature of future firms: Attributes of survivors in a changing world. Thousand Oaks, CA: Sage. 
James, E. H., \& Wooten, L. P. (2010). Leading under pressure. New York, NY: Routledge.

Jarvenpaa, S. L., \& Leidner, D. E. (1999). Communication and trust in global virtual teams. Organization Science, 6, 791-815.

Jehn, K. A., \& Mannix, E. A. (2001). The dynamic nature of conflict: A longitudinal study of intragroup conflict and group performance. Academy of Management Journal, 44, 238-251.

Kanki, B. G. (1996). Stress and aircrew performance: A team-level perspective. In J. E. Driskell \& E. Salas (Eds.), Stress and human performance (pp. 127-162). Mahwah, NJ: Lawrence Erlbaum Associates.

Kanki, B. G., Folk, V. G., \& Irwin, C. M. (1991). Communication variations and aircrew performance. International Journal of Aviation Psychology, 1, 149-162.

Kanki, B. G., \& Foushee, H. C. (1989). Communication as group process media of aircrew performance. Aviation, Space, \& Environmental Medicine, 60, 402-410.

Kanki B. G., Lozito S., \& Foushee H. C. (1989). Communication indices of crew coordination. Aviation, Space, and Environmental Medicine, 60, 56-60.

Kanki, B. G., Palmer, M. T., \& Veinott. E. S. (1991). Communication variations related to leader personality. Proceedings, 6th International Symposium on Aviation Psychology (pp. 253-259). Columbus, OH: Ohio State University.

Kerepesi, A., Jonsson, G. K., Miklósi, A., Topál, J., Csányi, V., \& Magnusson, M. S. (2005). Detection of temporal patterns in dog-human interaction. Behavioural Processes, 70, 69-79.

Klein, K. J., Ziegert, J. C., Knight, A. P., \& Xiao, Y. (2006). Dynamic delegation: Shared, hierarchical, and deindividualized leadership in extreme action teams. Administrative Science Quarterly, 51, 590-621.

Korsgaard, M. A., Schweiger, D. M., \& Sapienza, H. J. (1995). Building commitment, attachment, and trust in strategic decision-making teams: The role of procedural justice. Academy of Management Journal, 38, 60-84.

Kozlowski, S. W. J., Gully, S. M., Nason, E. R., \& Smith, E. M. (1999). Developing adaptive teams: A theory of compilation and performance across levels and time. In D. R. Ilgen \& E. D. Pulakos (Eds.), The changing nature of work performance: Implications for staffing, personnel actions, and development (pp. 240-292). San Francisco: Jossey-Bass.

Lacoursiere, R. (1980). The life cycle of groups: Group developmental stage theory. New York, NY: Human Sciences Press.

Lingard, L., Reznick, R., Espin, S., Regehr, G., \& DeVito, I. (2002). Team communication in the operating room: Talk patterns, sites of tension, and implications for novices. Academic Medicine, 77, 232-237.

Magnusson, M. S. (2000). Discovering hidden time patterns in behavior: T-patterns and their detection. Behavior Research Methods, Instruments, \& Computers, 32, 93-110.

Marks, M. A., Mathieu, J. E., \& Zaccaro, S. J. (2001). A temporally based framework and taxonomy of team processes. Academy of Management Review, 26, 356-376.

Marsch, S. C. U., Tschan, F., Semmer, N., Spychiger, M., Breuer, M., \& Hunziker, P. R. (2005). Performance of first responders in simulated cardiac arrests. Critical Care Medicine, 33, 963967.

McGrew, J. F., Bilotta, J. G., \& Deeney, J. M. (1999). Software team formation and decay: Extending the standard model for small groups. Small Group Research, 30, 209-234.

McKinney, E. H., Barker, J. R., Davis, K. J., \& Smith, D. (2005). How swift starting action teams get off the ground. Management Communications Quarterly, 19, 198-237.

Meyerson, D., Weick, K. E., \& Kramer, R. M. (1996). Swift trust and temporary groups. In R. Kramer \& T. Tyler (Eds.), Trust in organizations: Frontiers of theory and research (pp. 166195). Thousand Oaks, CA: Sage.

Mohrman, S. A., Cohen, S. G., \& Mohrman, A. M., Jr. (1995). Designing team-based organizations. San Francisco, CA: Jossey-Bass.

Moreland, R. L., (2010). Are dyads really groups? Small Group Research, 41, 251-267. 
Owens, D. A., Mannix, E. A., \& Neale, M. A. (1998). Strategic formation of groups: Issues in taskperformance and team member selection. In M. A. Neale, E. A. Mannix, \& D. H. Gruenfeld (Eds.), Research on managing groups and teams (pp. 149-166). Stamford, CT: JAI Press.

Paulus, P. (2000). Groups, teams, and creativity: The creative potential of idea-generating groups. Applied Psychology, 49, 237-262.

Peterson, R. S., Smith, D. B., \& Martorana, P. V. (2006). Choosing between a rock and a hard place when data are scarce and questions important: Reply to Hollenbeck, DeRue \& Mannor (2006). Journal of Applied Psychology, 91, 6-8.

Pinto, M. B., Pinto, J. K., \& Prescott, J. E. (1993). Antecedents and consequences of project team cross-functional cooperation. Management Science, 39, 1281-1297.

Potter, R. E., Cooke, R. A., \& Balthazard, P. A. (2000). Virtual team interaction: Assessment, consequences, and management. Team Performance Management, 6, 131-137.

Rasker, P. C., Post, W. M., \& Schraagen, J. M. C. (2000). Effects of two types of intra-team feedback on developing a shared mental model in command \& control teams. Ergonomics, 43, $1167-1189$.

Richardson, H. A., Vandenberg, R. J., Blum, T. C., \& Roman, P. M. (2002). Does decentralization make a difference for the organization? An examination of the boundary conditions circumscribing decentralized decision-making and organizational financial performance. Journal of Management, 28, 217-244.

Salas, E., Dickenson, T. L., Converse, S. A., \& Tannenbaum, S. I. (1992). Towards an understanding of team performance and training, In R.W. Swezey \& E. Salas (Eds.), Teams: Their training and performance (pp. 3-29). Norwood, NJ: Ablex.

Sarker, S., \& Sahay, S. (2003). Understanding virtual team development: An interpretive study. Journal of the AIS, 4, 1-38.

Schraagen, J. M., Huis in 't Veld, M., \& de Koning, L. (2010). Information sharing during crisis management in hierarchical vs network teams. Journal of Contingencies and Crisis Management, 18, 117-127.

Stachowski, A. A., Kaplan, S. A., \& Waller, M. J. (2009). The benefits of flexible team interaction during crises. Journal of Applied Psychology, 94, 1536-1543.

Sundstrom, E., De Meuse, K. P., \& Futrell, D. (1990). Work teams: Applications and effectiveness. American Psychologist, 45, 120-133.

Tschan, F., Semmer, N. K., Gautschi, D., Hunziker, P., Spychiger, M., \& Marsch, S. C. U. (2006). Leading to recovery: Group performance and coordinative activities in medical emergency driven groups. Human Performance, 19, 277-304.

Tuckman, B. W. (1965). Developmental sequence in small groups. Psychological Bulletin, 63, 384-399.

Tuckman, B. W., \& Jensen, M. A. C. (1977). Stages of small group development revisited. Group and Organizational Studies, 2, 419-427.

Uitdewilligen, S., \& Waller, M. J. (2011). Adaptation in multiteam systems: The role of temporal semistructures. In S. J. Zaccaro, M. A. Marks, \& L. DeChurch, (Eds.), Multiteam systems: An organizational form for dynamic and complex environments. London, UK: Taylor \& Francis.

Uitdewilligen, S., Waller, M. J., \& Zijlstra, F. R. H., (2010). Team cognition and adaptability in dynamic settings: A review of pertinent work. In G. P. Hodgkinson \& J. K. Ford (Eds.), International review of industrial and organizational psychology (Vol. 25, pp. 293-353). Chichester, UK: Wiley.

Waller, M. J. (1999). The timing of adaptive group responses to non-routine events. Academy of Management Journal, 42, 127-137.

Waller, M. J., Gupta, N., \& Giambatista, R. C. (2004). Effects of adaptive behaviors and shared mental models on control crew performance. Management Science, 50, 1534-1544.

Wheelan, S. (1994). Group processes: A developmental perspective. Boston: Allyn \& Bacon. 
Wheelan, S., \& Williams, T. (2003). Mapping dynamic interaction patterns in work groups. Small Group Research, 34, 443-467.

Wiener, E. L., Kanki, B. G., \& Helmreich, R. L. (1994). Cockpit resource management. New York: Academic Press.

Williams, K. D. (2010). Dyads can be groups (and often are). Small Group Research, 41, 268-274.

Zellmer-Bruhn, M., Waller, M. J., \& Ancona, D. (2004). The effect of temporal entrainment on the ability of teams to change their routines. In S. Blount (Ed.), Research on managing groups and teams (pp. 135-158). Oxford, UK: Elsevier.

Ziegert, J., Klein, K., \& Xiao, Y. (2001). Team leadership: A review and extension of existing theory through a qualitative study of shock trauma teams. In J. L. Pearce \& R. L. Tung (Eds.), Proceedings, Academy of Management Meeting (pp. 135-140). Washington, DC: Academy of Management. 